se debe que en los últimos año., los maestros hayan seguido tan espontáneamente a los comunistas. Hay que saber mirar la verdad cara a cara. Quienes crean la nueva vida, las nuevas formas de vida social, son los comunistas; ellos quienes desarrollan la función de aceleración cultural...

Niños ayer, hoy adolescentes. Se atienen al sabio precepto: en historia vivir no consiste en dejarse vivir, sino en preocuparse muy seriamente, muy conscientemente del vivir, como si fuera un oficio.-F. Ortúzar Vial.

LOS QUE NO FUIMOS A LA GUERRA, por W. Fernández Flórez.

El lector casual de libros humorísticos es siempre un hombre ingrato. Ríe y goza íisicamente con los chistes del libro, se entrega a él sin espíritu crítico alguno, se divierte. Pero, al final, dándose cuenta del tiempo que ha perdido leyendo el libro, tiempo que pudo aprovechar en una lectura más elevada y de más fruto, aparece en él el espíritu crítico y exclama:

\section{—iQué estupidez!}

Son muy pocos los libros humorísticos que se salvan de este último comentario, sobre todo si el lector los ha leído engañado por la propaganda o en un rato de distracción intelectual. El libro de Fernández Flórez, aunque sin admirativos, merece el comentario. Puede que esto sea en nosotros una irrespetuosidad hacia un autor de tanta venta y tan elogiosamente comentado en los periódicos de España, país donde el humorismo literario ha tallecido hace mucho tiemfo; pero así lo sentimos y lo decimos.

$\mathrm{Su}$ humorismo es un humorismo de brocha gorda, un humorismo de frases, no de ideas, que es el verdadero y el único humorismo que perdura en la literatura. Las situaciones de sus personajes no tienen nada de ingeniosas; su prosa es pesada y sus chistes también. Les falta espiritualidad.

Se empieza a leer el libro con cierto agrado. El primer capítulo ofrece más de lo que se encuentra y hasta la mitad del libro el lector no siente la vacuidad de la obra; pero a medida que avanzan los acontecimientos y se suceden las páginas, Fernández Flórez va perdiendo en el concepto del lector. ¿Esta es la novela que elogian tanto en España? La verdad, no vale la pena.... Lo que Gómez de Baquero, García Mercadal, López Prudencio, Díez-Canedo y Emilio Carrère dicen de la obra de Fernández Flórez, puede estar muy bien si se refiere a otros libros del mismo autor. Pero aplicado a Los que no fuimos a la guerra resulta exagerado y falso. Cuando se dedica, en la parte última del libro, a hablar de la mujer, provoca risa, no por los chistes que dice, sino por la seriedad con que habla. $-M$. $R$.

\section{BIOGRAFIA}

Sagasta o el Político, por el Conde de Romanones.

Decididamente, los españoles no tienen aliento biográfico. La colección de Vidas Españolas del siglo 